\title{
TURBULENCE STATISTICS MEASUREMENTS IN A NORTHERN HARDWOOD FOREST
}

\author{
M. G. VILLANI ${ }^{1}$, H. P. SCHMID ${ }^{1, \star}$, H.-B. SU ${ }^{1}$, J. L. HUTTON ${ }^{1}$ and C. S. VOGEL ${ }^{2}$ \\ ${ }^{1}$ Atmospheric Science Program, Dept. of Geography, Indiana University, Bloomington, Indiana, \\ 47405, U.S.A.; ${ }^{2}$ University of Michigan Biological Station, Pellston, Michigan, 49769, U.S.A.
}

(Received in final form 25 November 2002)

\begin{abstract}
Tower-based turbulence measurements were collected in and over a mixed hardwood forest at the University of Michigan Biological Station (UMBS) UMBS flux site in the northern summer of 2000. Velocity and temperature fluctuations were measured at five levels within the canopy (up to the canopy height, $H=21.4 \mathrm{~m}$ ), using one- and three-dimensional sonic anemometers and fine-wire thermocouples. Six additional thermocouples were distributed over the canopy-layer depth. Three-dimensional velocities and sonic temperatures were also measured above the canopy at $1.6 \mathrm{H}$ and at $2.15 \mathrm{H}$ on the AmeriFlux tower located at the UMBS $\sim$ flux site. Vertical profiles of buoyancy flux, mean horizontal velocity, Reynolds stress, and standard deviation and skewness of velocity components were calculated. The analysis of these measurements aims at a multi-layer parameterization framework of turbulence statistics for implementation in Lagrangian stochastic models. Turbulence profiles and power spectra above the canopy were analyzed in the context of MoninObukhov similarity theory (MOST) and Kolmogorov theory, as determined by stability at the top level $(2.15 H)$, to assess the extent to which surface scaling is valid as the canopy top is approached. Velocity spectra were computed to explore the potential of estimating the viscous dissipation rate, and results show that the high frequency range of the spectra above the canopy exhibits the roll-off predicted by Kolmogorov theory. Similarly, velocity standard deviations above the canopy converge to MOST predicted values toward the top level, and spectral peaks shift with stability, as expected. Within the canopy, both turbulence statistics profiles and spectral distributions follow the general known characteristics inside forests.
\end{abstract}

Keywords: Broadleaf forest, Canopy turbulence, Forest meteorology, Measurements, Turbulence spectra, Turbulence statistics.

\section{Introduction}

Turbulent atmosphere-biosphere exchanges of scalars and scalar fluxes play a very important role in weather and climate dynamics since they drive phenomena such as the global carbon and water cycles, which by interacting with the terrestrial radiation balance affect the temperature of the Earth's surface (IPCC, 2001; Baldocchi et al., 2000). The large-scale mechanisms of interaction between the two systems are often determined by small-scale processes. These are exchanges that take place through turbulent motion, which represents the most effective mechanism for transporting and mixing through the atmospheric layer closest to the Earth's surface, the

^ Corresponding author, E-mail: hschmid@indiana.edu 
atmospheric boundary layer (Campbell and Norman, 1998). Terrestrial vegetation plays an important role in such exchanges, but the detailed structure of turbulent exchange in tall canopies is still not completely understood. To better understand the small-scale processes in vegetated environments, long-term continuous measurements of scalars and scalar turbulent fluxes have been made in different canopy architectures and the study of turbulence in such environments has been steadily developing (e.g., Baldocchi and Hutchison, 1987; Baldocchi and Meyers, 1988; Gao et al., 1989; Amiro, 1990; Kaimal and Finnigan, 1994; Raupach et al., 1996; Kruijt et al., 2000).

Knowledge about turbulent characteristics in vegetated environments becomes fundamental to initialize and evaluate analytical and numerical models. Some of these models, diffusion models in particular, constitute complementary tools to field campaigns since they allow a more detailed evaluation of processes and meteorological phenomena. In general, such models require the specification of turbulence structure in the domain where they operate. Due to the lack of a closed theory, this is often based on the analysis of measured turbulence statistics profiles.

Observations and theoretical considerations suggest that turbulence has different characteristics in different regions of the atmospheric boundary layer. For this reason the atmospheric boundary layer is conveniently structured into several conceptual sublayers. Here, we define a basal layer as the layer closest to the forest floor, characterized by weak flow that vanishes at the forest floor. The canopy layer extends from the basal layer up to the canopy top. Here turbulence is expected to be largely controlled by coherent structures of the same scale as the canopy height (Raupach, 1989). These structures consist of the fast incursions of gusts and sweeps entering the canopy from the flow above the vegetation, and are generated by perturbations in the wind shear that builds up at approximately the canopy height. Over rough vegetated surfaces the height range up to about twice the canopy height $(H)$ is often considered as the roughness layer. This layer represents a transition where the air flow is influenced by wakes generated both mechanically and thermally at scales associated with individually roughness elements. Due to local-scale advection, the turbulence field is often not horizontally uniform here, even in a time average, and must be considered three-dimensional (Roth, 2000). Although there have been several studies on the structure of the roughness layer (or transition layer) over tall canopies (e.g., Garratt, 1978, 1992; Raupach et al., 1980; Chen and Schwerdtfeger, 1989; Högström et al., 1989; Brunet et al., 1994; Simpson et al., 1998), our knowledge of turbulence statistics in this region is rather poor and empirical. Furthermore, these studies show that similarity theory generally underestimates scalar fluxes in this layer. Above $2 H$ the roughness layer merges into the surface layer (often termed also the inertial sublayer). Here, mean profiles of turbulence statistics obey semi-logarithmic laws or their diabatic extensions, and Monin-Obukhov similarity theory, MOST, often applies. Above is the mixed layer, which develops during daytime and is characterized by vigorous convection. Here, turbulence properties are assumed to be independent of the surface roughness, and 
mixed-layer similarity theory applies. At night, turbulence and mixing often decay as radiative cooling of the surface generates the development of a shallow nocturnal boundary layer characterized by statically stable air with weak and intermittent turbulence. During the non-turbulent periods, the flow aloft is often found to be decoupled from the surface, even over non-vegetated surfaces (e.g., Stull, 1988).

This work presents measured turbulence statistics from a mixed hardwood forest at the University of Michigan Biological Station (UMBS), including vertical profiles of temperature, heat flux, mean velocity, momentum flux, and higherorder turbulence statistics. Moreover, composite power spectra of temperature and velocity are discussed. Profiles and spectra of vertical turbulence statistics were organized into five atmospheric stability classes (determined above canopy). The differences among them, and their relation to the turbulent motion throughout the canopy, are discussed. The motivation of this work is to explore canopy transport and air motion features in the canopy layer, such as used in Lagrangian stochastic diffusion models (LS models) to simulate turbulent dispersion in a forest environment, for instance as applied in footprint models (Schmid, 2002).

\section{Site and Instrumentation}

Measurements were conducted at the UMBS flux tower site (Figure 1), which lies within 4,047 ha of mixed forest on UMBS land near Pellston, in the northern lower peninsula of Michigan, U.S.A. $\left(45^{\circ} 35^{\prime} \mathrm{N}, 84^{\circ} 42^{\prime} \mathrm{W}\right)$. Pearsall (1995) provides a detailed description of the study area.

The UMBS flux site lies on a fertile high outwash plain at an elevation of 234 m approximately $1.25 \mathrm{~km}$ south of Douglas Lake and $3.5 \mathrm{~km}$ north-west of Burt Lake (Figure 1). The stand age in this area is approximately 90 years, and the mean canopy height $(H)$ is about $22 \mathrm{~m}$. The area is entirely forested, with bigtooth and trembling aspen dominating within a $1-\mathrm{km}$ radius, but with significant representation by red oak, beech, sugar maple, white pine, and hemlock. Prevailing winds are from the north-west, traversing the aspen dominated Pellston Plain. The most significant topographic feature in the area is the crest of the interlobate moraine approximately $1 \mathrm{~km}$ to the south-west of the site. Two small paved roads lie 100 $\mathrm{m}$ east and $300 \mathrm{~m}$ south, and a number of residences are clustered along the lake shore to the north.

The principal structure of the UMBS $\sim$ flux site is the $46 \mathrm{~m}$ tall AmeriFlux tower, a self-supporting steel structure with a triangular cross section. It has a base of 5.1 $\mathrm{m}$ side-length and tapers to $1.8 \mathrm{~m}$ at $30.5 \mathrm{~m}$ height. At about $30 \mathrm{~m}$ distance, a 24.4 $\mathrm{m}$ tall and $0.3 \mathrm{~m}$ triangular cross-section lightweight aluminum structure (the 'Canopy tower') is supported by guy wires. The Canopy tower permits measurements at different levels within the forest, with minimal interference with the canopy architecture. 


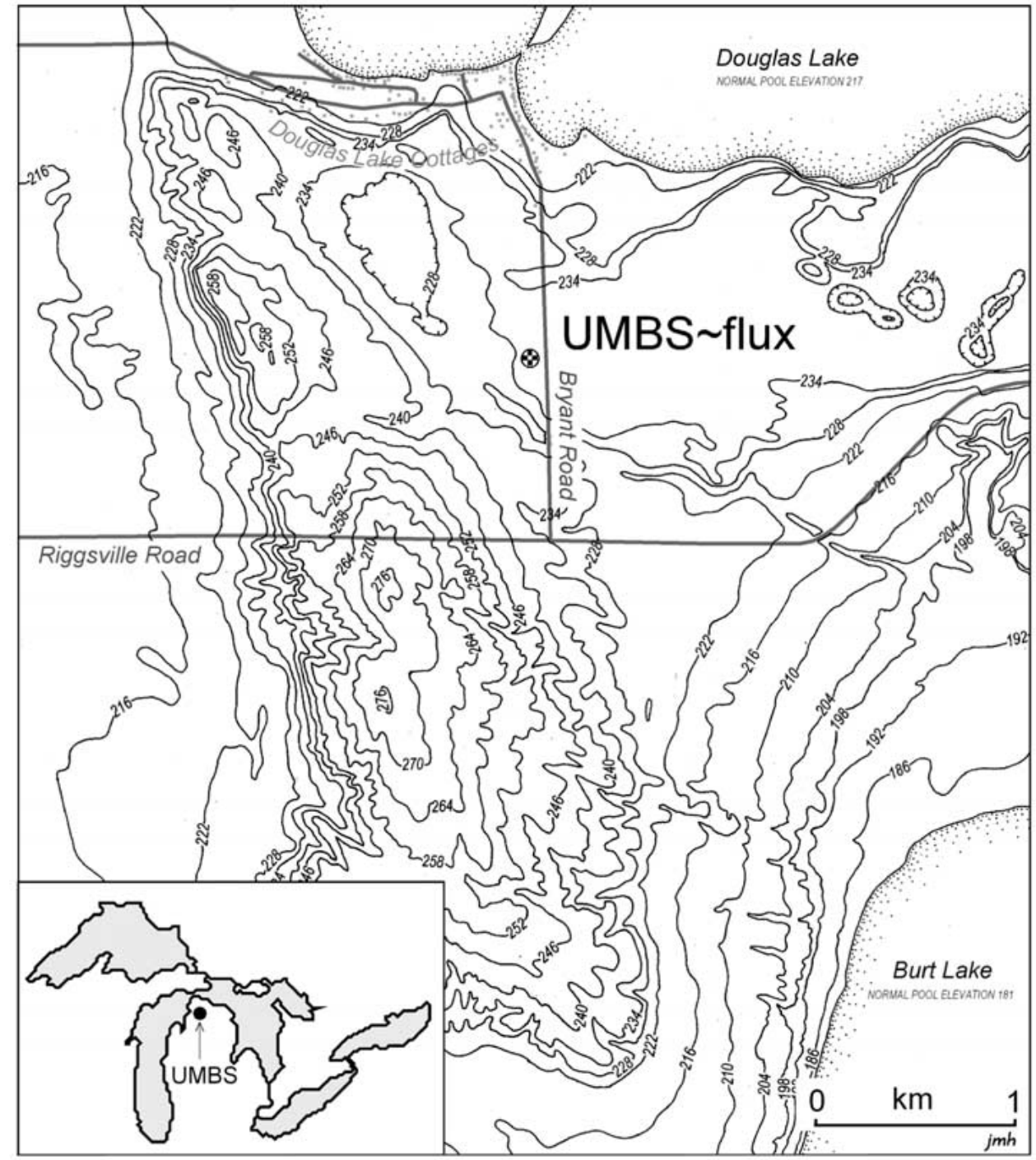

Figure 1. Map of the location of UMBS flux site, in the north Michigan's lower peninsula (U.S.A.). The location of the tower is indicated by the symbol 0 . Access to the tower is from an unimproved driveway off Bryant Road.

Measurements for the present study were collected from July 6 (188 doy, day of the year) to July 312000 (213 doy). Three three-dimensional (3-D) sonic anemometers (CSAT3, Campbell Scientific, Inc., Logan UT), four one-dimensional (1-D) sonic anemometers (CA27, Campbell Scientific) and ten fine-wire thermocouples (Omega TC, type T copper-constantan, Omega Engineering, Inc.) were used to collect data at fixed levels within and above the canopy, and were set up to operate at a sampling frequency of $10 \mathrm{~Hz}$. During this time the maximum vegetation-area 
index (VAI), was estimated to be 3.9 ( $\mathrm{Su}$ et al., 2000b). The vegetation density profile exhibited two relative maxima of dense foliage (Figure 2): One at approximately $0.8 \mathrm{H}$, corresponding roughly to the middle of the crown of the mature aspen trees, and the other at about $0.1 \mathrm{H}$, associated with the maximum foliage density of young white pines in the understory. A relatively open trunk space was located between $0.3-0.6 \mathrm{H}$. To account for this specific canopy architecture, one 3 -D sonic anemometer was mounted on a horizontal boom at the canopy height, and the 1-D anemometers and fine-wire thermocouples were set up on horizontal booms at different heights inside the canopy (Table I and Figure 2). The 1-D sonic anemometers were oriented in the vertical axis (over the level local terrain) by the integrated bubble levels, and their position was controlled and adjusted regularly. Due to their sensitivity to water, the 1-D sonic anemometers needed to be covered with waterproof bags when rain threatened. Thermocouples were installed below the booms or anemometer arms, to protect them from direct sunlight. All measurements from the Canopy tower were recorded on a data logger (CR 5000, Campbell Scientific), and the logger panel temperature acted as the reference temperature for the thermocouples. Data were downloaded to a magnetic-optical (MO) drive every 20 minutes. Above the canopy, wind velocity and temperature were sampled with two 3-D sonic anemometers (CSAT3) on the AmeriFlux tower as in Table I. These measurements are continuously collected by the UMBS $\sim$ flux project, and data acquisition is described in Schmid et al. (2003).

\section{Data Analysis}

\subsection{QuALITY CONTROL}

Non-precipitation period data were organized into hourly files, which were checked to detect spikes using the quality control methods described by Schmid et al. (2000). Since all data collected during precipitation periods were rejected, the quality control analysis focused on the detection of 'soft spikes', which represent short-lived departures from calculated hourly means above a certain threshold (see Schmid et al., 2000, for a detailed description of the approach). In the entire dataset, very few soft spikes were detected, and their number was so sparse that they were not removed, but considered an acceptable amount of noise for the computation of composite power spectra.

\subsection{Potential temperature AND heat FluXes}

Data from thermocouples and sonic anemometers were used to compute hourly statistics of temperature and heat fluxes. Hourly means for temperature from the thermocouples and hourly humidity profiles from both towers were used to convert the thermocouple temperatures to approximate virtual potential temperatures, so that they can be compared to the sonic anemometer-derived potential temperatures. 

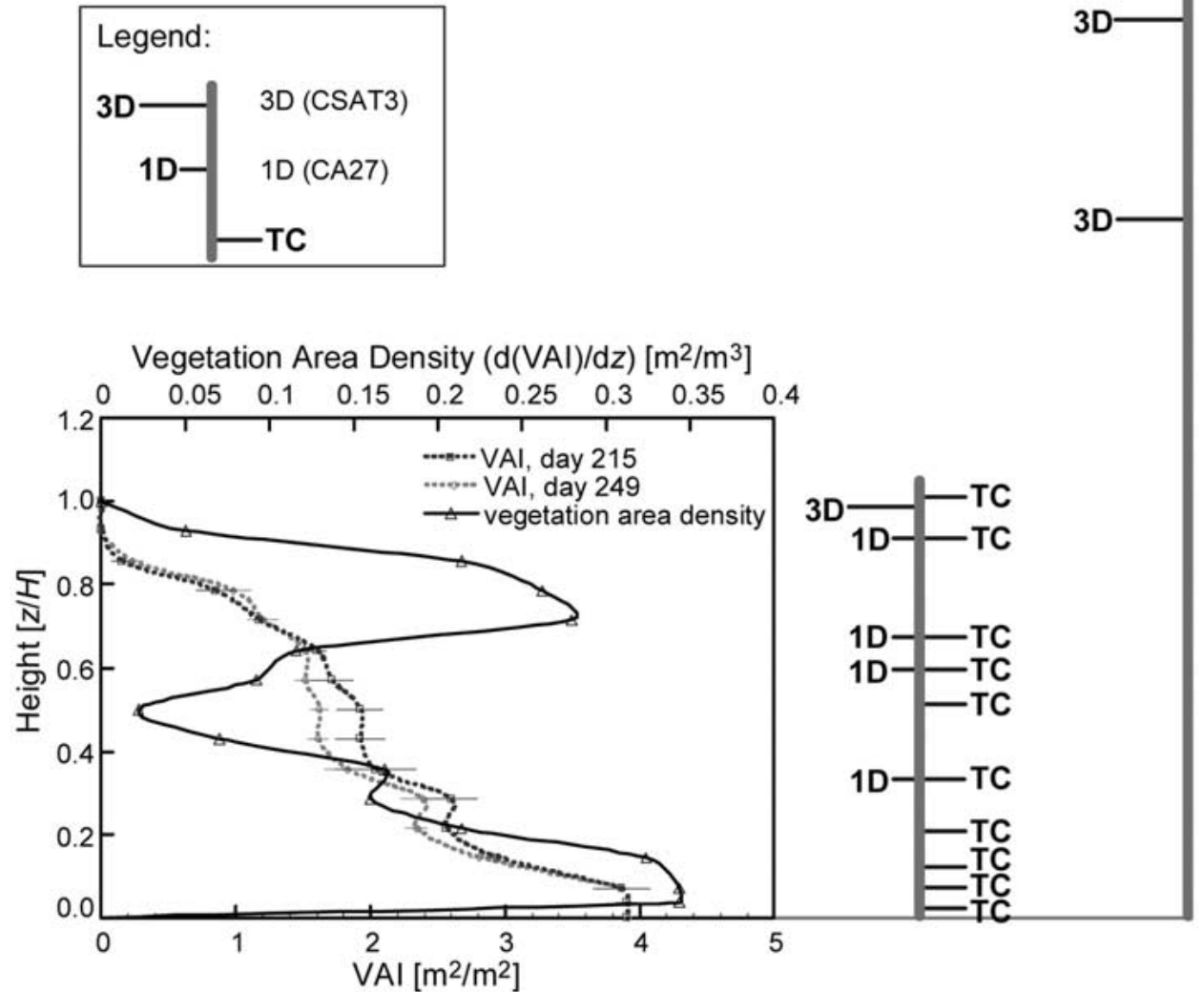

Figure 2. Vegetation density profile at UMBS and instrument locations (to scale). In the vegetation density graph, the dashed curves represent the cumulative VAI measured at two different days; and the bold curve shows the derived foliage density distribution, $a$, with height. In the schematic representation of the instrument locations.

Hourly values of virtual potential temperature and heat flux for the entire measurement period were ensemble-averaged according to the hour of the day. Within the distribution of values for each day-hour, deviations from the mean of more than three standard deviations were considered outliers and were not used for further analysis.

\subsection{VELOCITY STATISTICS}

The velocity components of the 3-D sonic anemometers were rotated to align their frame of reference to the natural direction of the horizontal mean flow coordinates (McMillen, 1988). The rotated 3-D data were then used to compute the horizontal mean wind $(U)$, momentum flux $(-\overline{u w})$, where $u$ and $w$ indicate the deviations from the mean values $U$ and $W$ respectively, and the overbar denotes a Reynolds average. Standard deviations $\left(\sigma_{u, v, w}\right)$ and skewnesses $\left(S k_{u, v, w}\right)$ of the velocity components were also computed. Data from the 1-D sonics were used to 
TABLE I

Locations of thermocouples (TC), 1-D (CA27) sonic anemometers, and 3-D (CSAT3) sonic anemometers above and within the canopy, where $z / H$ represents the normalized height; $z$ the height above ground expressed in metres, and $H$ is the canopy height.

\begin{tabular}{lcllll}
\hline Location & $z / H$ & $z(\mathrm{~m})$ & TC & 1-D & 3-D \\
\hline AmeriFlux Tower & 2.15 & 46 & & & $*$ \\
& 1.60 & 34 & & & $*$ \\
Canopy Tower & 1.04 & 22.2 & $*$ & & \\
& 1.00 & 21.4 & & & $*$ \\
& 0.90 & 19.2 & $*$ & $*$ & \\
& 0.72 & 15.4 & $*$ & $*$ & \\
& 0.61 & 13 & $*$ & $*$ & \\
& 0.52 & 11.1 & $*$ & & \\
& 0.51 & 11 & & & \\
& 0.33 & 7.1 & $*$ & $*$ & \\
& 0.23 & 5 & $*$ & & \\
0.15 & 3.3 & $*$ & & \\
& 0.15 & 3.2 & & & \\
& 0.04 & 0.9 & $*$ & & \\
& 0.02 & 0.5 & $*$ & & \\
\hline
\end{tabular}

compute sensible heat fluxes, standard deviation $\left(\sigma_{w}\right)$ and skewness $\left(S k_{w}\right)$ of the vertical velocity component within the canopy. These quantities were normalized in the following way: Mean wind as $U / U(H)$; momentum flux as $-\overline{u w} /\left(u_{*}\right)^{2}$, with $u_{*}=\left(\overline{u w}_{t o p}\right)^{1 / 2}$ representing the friction velocity at the top level of measurements $(46 \mathrm{~m})$; standard deviations as $\sigma_{u} / u_{*}=\left(\overline{u^{2}}\right)^{1 / 2} / u_{*}, \sigma_{v} / u_{*}=\left(\overline{v^{2}}\right)^{1 / 2} / u_{*}$, $\sigma_{w} / u_{*}=\left(\overline{w^{2}}\right)^{1 / 2} / u_{*}$; the velocity components skewness $\left(S k_{u}, S k_{v}, S k_{w}\right)$ as $\overline{u^{3}} / \sigma_{u}^{3}$, $\overline{v^{3}} / \sigma_{v}^{3}$, and $\overline{w^{3}} / \sigma_{w}^{3}$. We used the value of the friction velocity at the top level of measurements as a normalization factor, assuming that it represents surface-layer conditions, to discern deviations from surface-layer similarity theory predictions. The same normalization was adopted by Raupach et al. (1996) and Kaimal and Finnigan (1994).

\subsection{SPECTRAL ANALYSis}

Velocity power spectra $S_{u}, S_{v}$, and $S_{w}$ were computed from the 3-D sonic anemometers. In addition, power spectra were also calculated for the sonic temperatures. For each variable, the $10 \mathrm{~Hz}$ measurements were organized in time series of approx- 
imately 54 minutes (equivalent to $N=2^{15}$ data points). Time series were linearly detrended, and a tapering window was applied to minimize spurious frequencies in the spectral distribution caused by non-periodicity of the finite time series. The window used has the shape of a bell taper:

$$
\begin{array}{ll}
y_{i}=\frac{1-\cos \left(10 \pi\left(\frac{i}{N}\right)\right)}{2} & \text { for } \quad \frac{i}{N} \leq 0.1, \\
y_{i}=1 & \text { for } \quad 0.1 \leq \frac{i}{N} \leq 0.9, \\
y_{i}=\frac{1+\cos \left(10 \pi\left(\frac{i}{N}\right)\right)}{2} & \text { for } \quad \frac{i}{N} \geq 0.9,
\end{array}
$$

where $i$ is the position within a time series of length $N$. Here this window is called the split-cosine window, and preserves $80 \%$ of the original amplitudes in the time series, which represents a larger percentage of the original amplitudes of the signal compared to the percentage preserved by the generally recommended Welch window (Press et al., 1997). A comparison between the two showed that the split-cosine window preserves the low frequencies better (see also Justice, 1981).

A Fast Fourier Transform, FFT (Press et al., 1997), was applied to each 54minute time series and power spectra were calculated. To compare the results for similar stability conditions, the power spectra and frequencies were normalized in the following way:

$$
\begin{aligned}
& \hat{S}(f) \rightarrow \frac{f S(f)}{\sigma^{2}}, \\
& \hat{f} \rightarrow f \frac{H}{U(H)},
\end{aligned}
$$

where $S$ and $\hat{S}$ are the power spectrum and the normalized power spectrum respectively, $\sigma^{2}$ is the variance of the time series, $f$ and $\hat{f}$ the natural frequency and the non-dimensional normalized frequency respectively, and $U(H)$ is the mean velocity at the canopy height. The variables $H, U(H)$, and $\sigma^{2}$ were chosen as normalization factors since it has been suggested that turbulence within the canopy may be scaled with these variables (e.g., Raupach et al., 1996; Su et al., 1998). For consistency, this canopy specific normalization was applied to the power spectra both inside and above the vegetation, because the emphasis of this work is on canopy turbulence. This approach allows the comparison of the spectral distributions at different vertical levels, and was also adopted in Kaimal and Finnigan (1994). For each normalized frequency decade, normalized power spectra were then bin averaged using 50 logarithmically spaced intervals.

To better present the shape of the power spectra, a locally weighted scatterplot smoothing method, LOWESS (Cleveland, 1979), was applied to the nondimensional spectral distributions as shown in Figure 3. This figure illustrates 


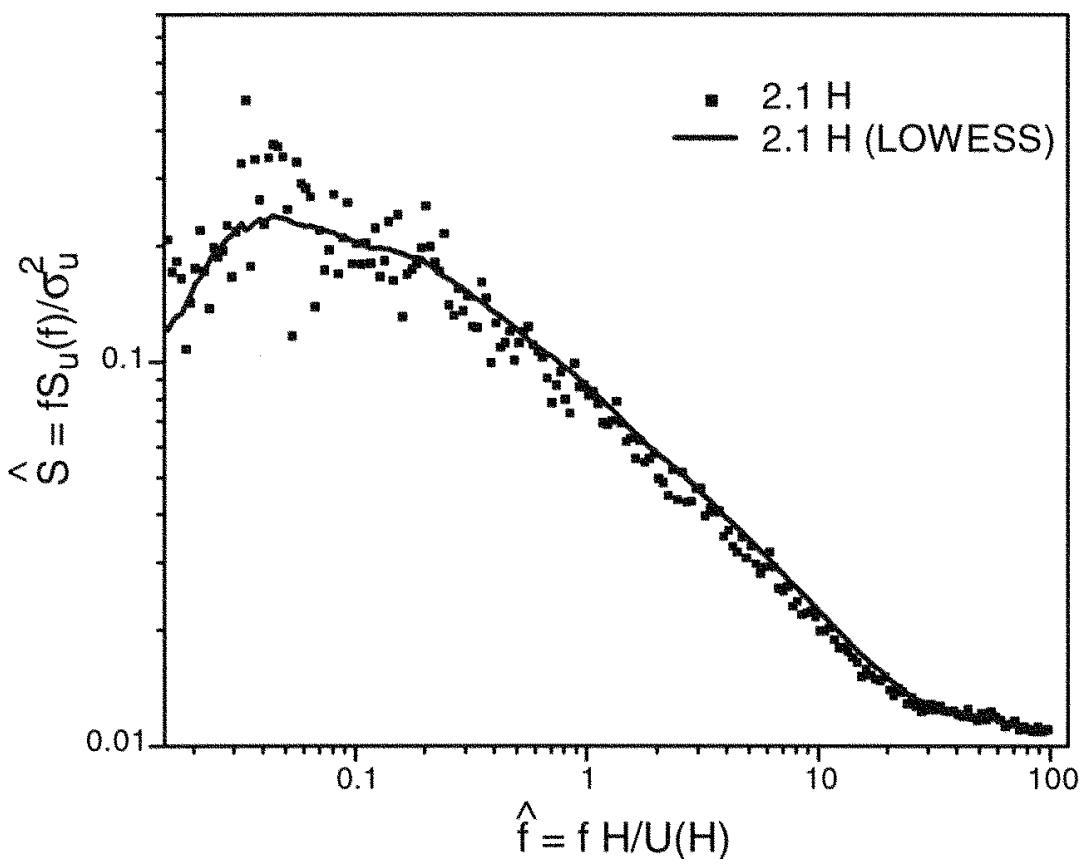

Figure 3. Example of the LOWESS representation of composite spectra. The data shown are normalized spectral densities and non-dimensional frequencies for the $u$ component at $2.15 \mathrm{H}$ in very unstable conditions (VU). The dots represent the original composite spectral distribution. The solid line is the corresponding LOWESS curve.

the distribution of scatter. In the spectra that are presented below, the (nondimensional) frequency range of $\hat{f}>40$ is omitted.

\subsection{Stability Classes}

To analyze the behaviour of the turbulence statistics and spectra in more detail, and to detect variations with surface-layer stability above the canopy, hourly turbulence quantities and composite power spectra were divided into five stability classes, based on the Obukhov lengths at $1.6 \mathrm{H}$ and $2.15 \mathrm{H}$. The stability classes were defined as shown in Table II. The term $z_{t o p}$ is the top height of measurement $(2.15 H)$, and $d$ is the displacement height $(0.8 H$, Su et al., 2000b), and $L$ is the Obukhov length calculated at $2.15 H$ (only hourly measurements with $L$ values in the same stability class for both the levels $2.15 \mathrm{H}$ and $1.6 \mathrm{H}$ were considered in this study). For each class, averaged hourly turbulence statistics and composite power spectra were computed. As for temperature and heat fluxes, deviations from the mean of more than three standard deviations were omitted from further analysis. 
TABLE II

Stability classes defined above the canopy, at $2.15 H$.

\begin{tabular}{llll}
\hline Stability & Obukhov length & Abbreviation & $\begin{array}{l}\text { Number of } \\
\text { hourly runs }\end{array}$ \\
\hline Very Unstable & $-1<\frac{z_{\text {top }}-d}{L}<-0.3$ & $\mathrm{VU}$ & 12 \\
Moderately unstable & $-0.3 \leq \frac{z_{\text {top }}-d}{L} \leq-0.05$ & $\mathrm{MU}$ & 30 \\
Near neutral & $-0.05<\frac{z_{\text {top }}-d}{L}<0.05$ & $\mathrm{NN}$ & 9 \\
Moderately stable & $0.05 \leq \frac{z_{\text {top }}-d}{L} \leq 0.2$ & $\mathrm{MS}$ & 8 \\
Stable & $0.2<\frac{z_{\text {top }}-d}{L}<1$ & $\mathrm{ST}$ & 7 \\
\hline
\end{tabular}

\section{Results}

\subsection{Potential temperatures And heat FluXes}

Mean values of virtual potential temperature covered a range from 11 to $24{ }^{\circ} \mathrm{C}$ during the period of measurement. They usually reached the lowest values in early morning, at about 0600 to $0700 \mathrm{~h}$, and maximum values at 1500 to $1600 \mathrm{~h}$. Sensible heat fluxes (Figure 4) followed the overall daily cycle usually found in the literature (see Oke, 1987, for example). During the period of measurement, their values ranged from about -20 to $300 \mathrm{~W} \mathrm{~m}^{-2}$. At all levels there was a dip in the flux values between 1200 and $1600 \mathrm{~h}$. The cause of the dip could not be identified, but it occurred consistently on most measurement days (not shown here).

The virtual potential temperature profiles, presented here as differences from the canopy top value, $\Delta \theta_{v}=\theta_{v}-\theta_{v}(H)$, are shown for five periods of the ensemble-average day (Figure 4a): 0000, 0800, 1200, 1400, and $2000 \mathrm{~h}$. These hours were chosen since they represent the mean diurnal trend in the potential temperature profile inside and above the canopy. At midnight, potential temperatures increased continuously from the forest floor to the levels above the canopy. This trend suggests that stable atmospheric conditions dominated the motion both inside and above the forest. At this time, heat fluxes (Figure $4 b$ ) were negative above the vegetation and have near zero values inside the canopy. In the early morning $(0800 \mathrm{~h})$, stable conditions were still present within the canopy. Here, heat fluxes became positive in the canopy layer and above the vegetation, and a clear flux divergence started to develop between the values above the forest and inside the canopy (Figure 4b). Between late morning and early afternoon, the sensible heat fluxes above canopy were more than twice the magnitude of those within the canopy, likely due to reduced available energy in the vegetation. At these times (1200 and $1400 \mathrm{~h}$ ), the vertical temperature profiles were near neutral or slightly unstable. Here, similar values in the potential temperature profiles are indicative of 

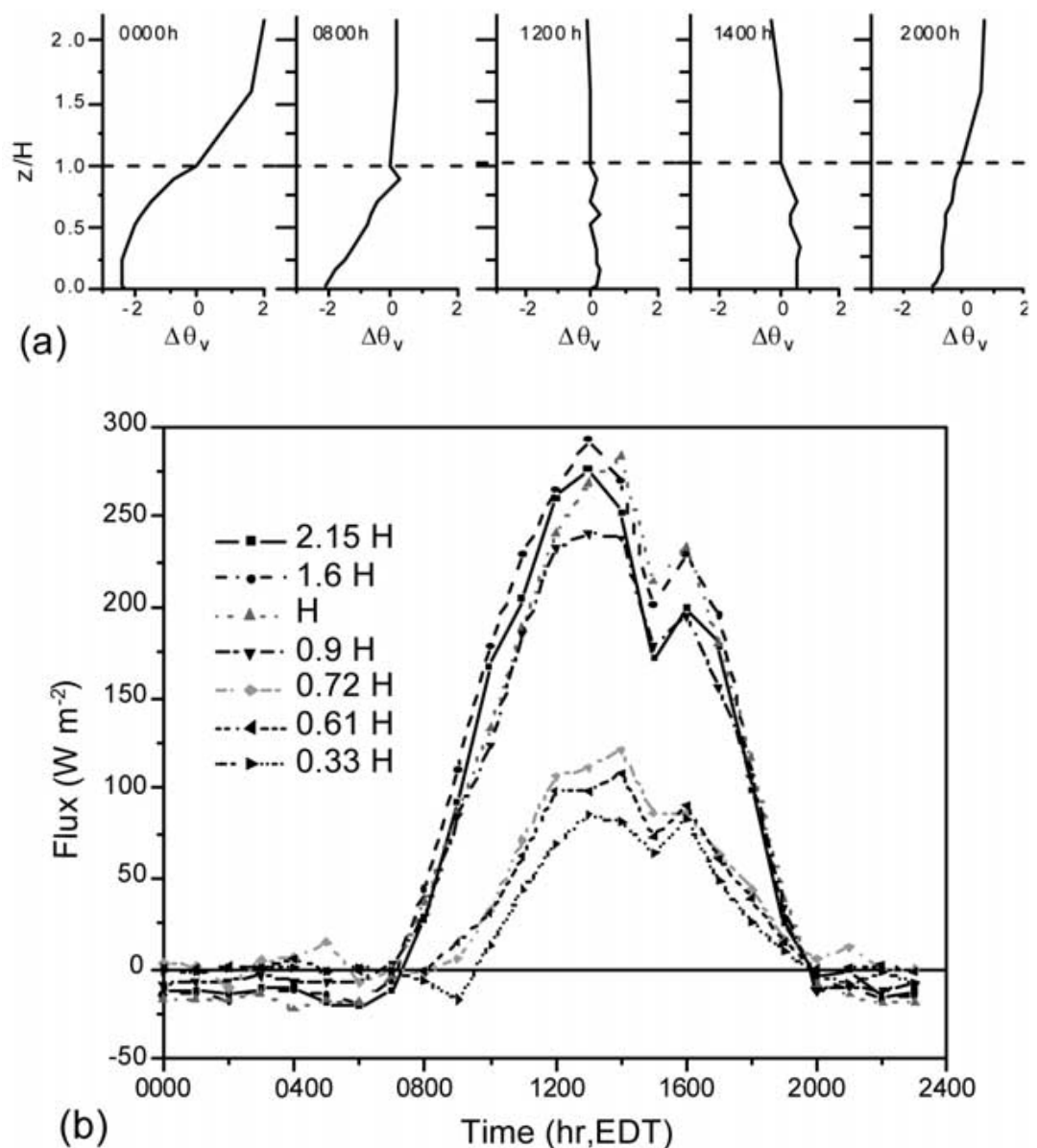

Figure 4. Thermal structure in and over the forest canopy. Mean daily pattern of (a) potential temperature difference profiles $\left(\Delta \theta_{v}=\theta_{v}-\theta_{v}(H)\right)$ for $0000,0800,1200,1400$, and $2000 \mathrm{~h}$, and (b) sensible heat fluxes. Means are for all available days.

efficient turbulent mixing during daytime. In the evening, the potential temperature profile (at $2000 \mathrm{~h}$ ) indicates that stable atmospheric conditions developed at canopy height, while below the stratification was still near neutral. This development is also reflected in Figure 4b: The sensible heat flux profile assumed its nighttime regime shortly before $2000 \mathrm{~h}$.

\subsection{Turbulence PROFILES}

Figure 5 illustrates the characteristics of $\left(z_{t o p}-d\right) / \Lambda, U / U(H)$, and $-\overline{u w} / u_{*}^{2}$, where $\Lambda$ is an Obukhov length calculated at $2.15 H, 1.6 H$ and $H$, with local values of $-\overline{u w}$, and sensible heat flux. In ideal surface-layer conditions (as in the MoninObukhov similarity theory, MOST, see Stull, 1988), these profiles are expected to 
be constant or clearly defined. Values for $\left(z_{t o p}-d\right) / \Lambda$ above canopy show the characteristic mean values for the atmospheric stability classes defined in Section 3.5. For all classes, the top levels 1.6 and $2.15 H$ fell within the same class, within the margins of variability. Differences from the values at $2.15 \mathrm{H}$ were found at the canopy top for stable, moderately stable and very stable conditions, characterized by $\left(z_{\text {top }}-d\right) / \Lambda$ values slightly smaller than at the $2.15 \mathrm{H}$ level. The height variations of $\Lambda$ are primarily due to friction velocity (see below), as sensible heat flux did not vary significantly with height above the canopy (see Figure $4 b$ ).

Profiles of the normalized momentum stress, $-\overline{u w} / u_{*}^{2}$ (Figure $5 \mathrm{~b}$ ), give some indication of the structure of the air flow above the forest in different stability conditions. With the exception of the stable and unstable cases, the values of $-\overline{u w} / u_{*}^{2}$ were similar at all heights, suggesting that the two top heights exhibit surface-layer characteristics (Figure 5b). Deviations at $H$ for the unstable, moderately unstable case, where $-\overline{u w} / u_{*}^{2}$ was smaller, were likely due to taller than average trees, which can extract momentum even slightly above the average canopy height, $H$. In the stable case, the momentum flux at $H$ and $1.6 H$ was significantly higher than at the $2.15 \mathrm{H}$ level. We suspect that the flow may have been decoupled between the two top layers in this case. This observation is supported by the higher values of $-\overline{u w} / u_{*}^{2}$ at the lower levels, which suggests that more energy was available, and turbulence further enhanced. Local advection of momentum may have been present in these layers as well. The profiles for the normalized mean wind $U / u_{*}$ in different stability conditions are shown in Figure $5 \mathrm{c}$. The curves for different stability classes generally agree with the expected trend in the surface layer, which predicts a logarithmic relation in near-neutral conditions, with an increase in the vertical velocity gradient in stable conditions and a decrease in unstable conditions (see Oke, 1987, for example).

Measured turbulence statistics of the flow above and within the canopy are presented in Figure 6. Within the canopy only $\sigma_{w}$ and $S k_{w}$ were available from the 1-D anemometers. Above the forest, profiles generally agree with surfacelayer expectations for near-neutral conditions: viz. $\sigma_{u} / u_{*} \approx 2.3, \sigma_{v} / u_{*} \approx 1.7$, $\sigma_{w} / u_{*} \approx 1.25$ (e.g., Amiro, 1990a; Brunet et al., 1994; Raupach et al., 1996; Rannik et al., 2000). At the top level, $\sigma_{u} / u_{*}$ is smaller than expected. Variations in all components are particularly large for stable conditions, which may be attributable in part to error enhancement when $u_{*}$ is small. As discussed in the case of $-\overline{u w} / u_{*}^{2}$ (Figure 5), vertical decoupling of the flow or advection may also play a role here.

The patterns for $\sigma_{w} / u_{*}$ and $S k_{w}$ (Figures 6c and 6f) illustrate the vertical inhomogeneity of the flow above and within the canopy. $\sigma_{w} / u_{*}$ decayed rapidly with decreasing height within the canopy, until it reached values close to zero just above the forest floor. Similar inhomogeneity is seen in $S k_{w}$, while values at the top are slightly positive, vertical skewness within the canopy is negative, but shows a rather complex structure (Figure 6f). Variations with surface-layer stability were small above and near the canopy top, but increased towards the forest floor. The skewness did not vary strongly (or slightly increased) in the crown layer (between about 0.9 

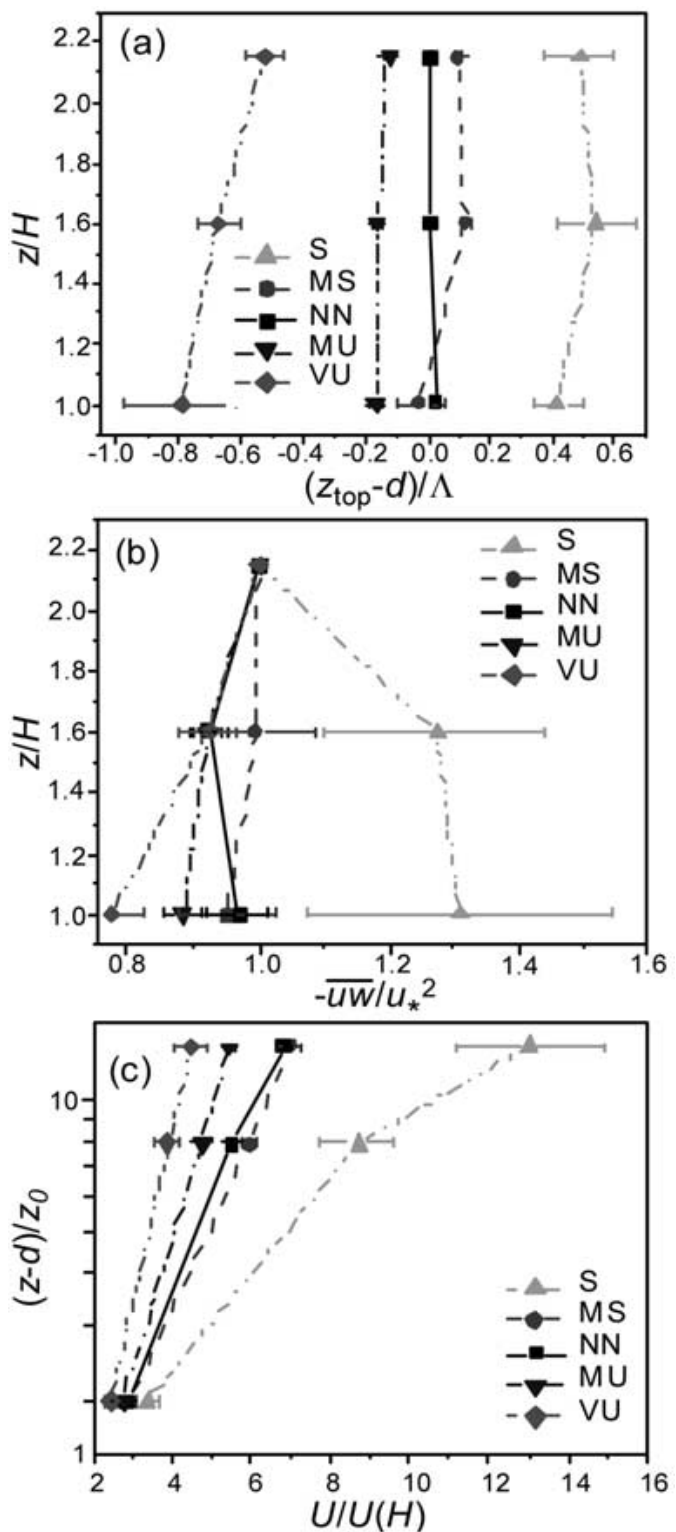

Figure 5. Variations from standard surface layer conditions with height: (a) Obukhov length $($ ztop $-d) / \Lambda$ (where $\Lambda$ is the local Obukhov length); (b) normalized Reynolds stress $-\overline{u w} / u_{*}^{2}$; (c) normalized mean wind, $U / U(H)$ at different heights and in different stability conditions (see also Table II). The displacement height $d=0.8 H$, and the roughness length $z_{0}=0.1 H$ (see Su et al., 2000b). Error bars represent one standard deviation on each side. 

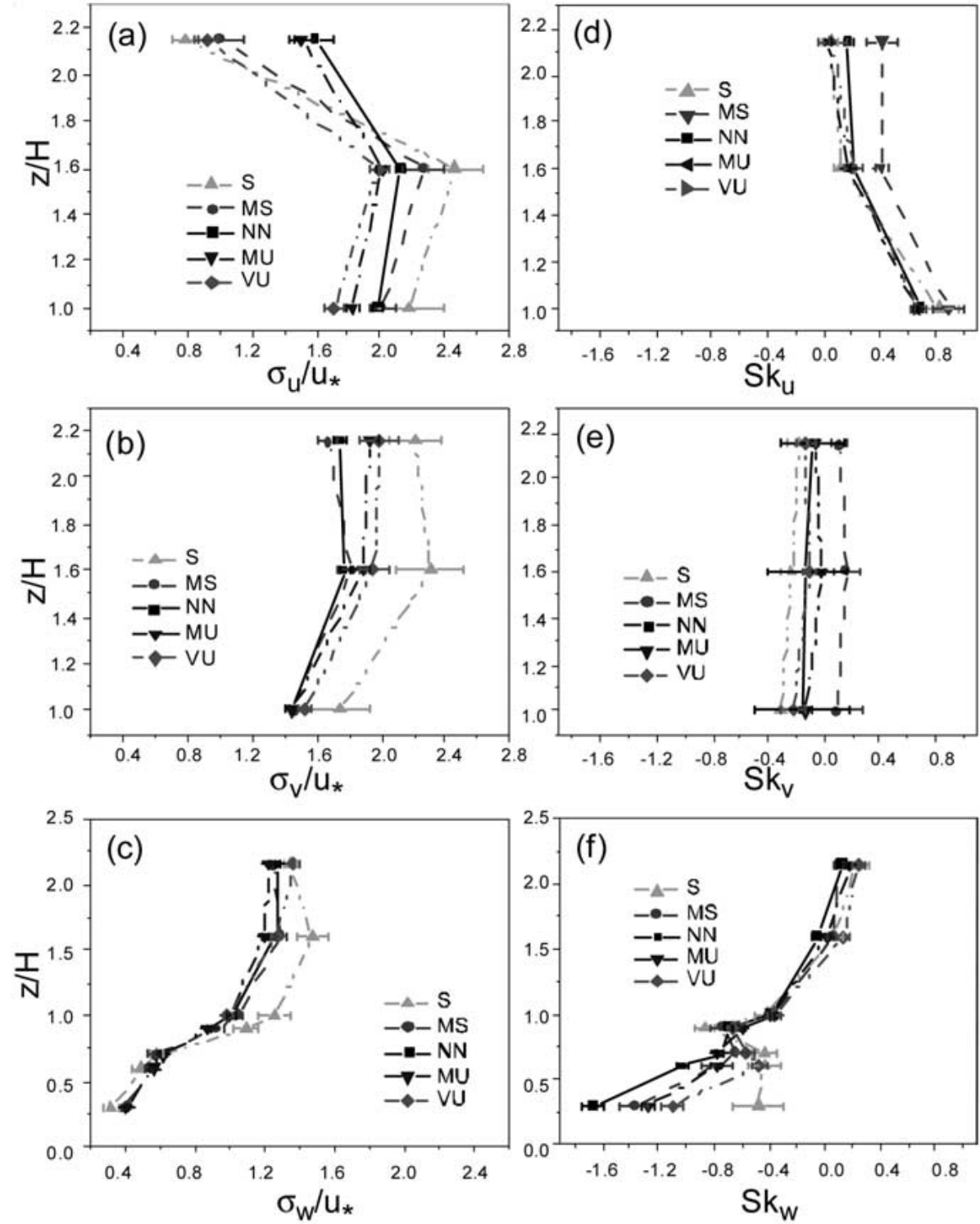

Figure 6. Normalized standard deviations of velocities (left panels) and velocity skewness (right panels) at different heights and stabilities, (a) $\sigma_{u} / u_{*}$, (b) $\sigma_{v} / u_{*}$, (c) $\sigma_{w} / u_{*}$, and (d) skewness $S k_{u}$, (e) $S k_{v}$, (f) $S k_{w}$ (see also Table II). Error bars represent one standard deviation on each side. 
and $0.6 \mathrm{H}$ ), where the $\sigma_{w}$ gradient is strongest (compare, Figure 6c). Except in the stable case, vertical velocity was most negatively skewed near the forest floor. Above the canopy $S k_{u}$ was close to zero at the top heights $(2.15 \mathrm{H}, 1.6 \mathrm{H})$, in agreement with surface-layer predictions, and its values increased towards the canopy top. Although values for $S k_{u}$ are not available within the canopy, the picture that emerges is consistent with the association of positive $S k_{u}$ and negative $S k_{w}$ within the canopy, due to fast and intense incursions of downward-moving, high-speed sweeps from above ( $w<0, u>0$, see, e.g., in Brunet et al., 1994, or Raupach et al., 1996). These structures are shown to be generated by perturbations in the shear stress that build up at about canopy height (e.g., Su et al., 1998, 2000a). The $S k_{w}$ values at the forest floor indicate that high velocity sweeps were more frequent and effective in the near-neutral surface-layer case, when $S k_{w}$ has the largest negative value (about -1.6 ), and they were suppressed in stable conditions characterized by the smallest values in magnitude (about -0.5 ). During stable conditions, the most negative value for $S k_{w}$ was found near the canopy top, whereas values lower in the canopy are closer to zero. This result may suggest a decoupling between the motion above the canopy and the flow inside the vegetation. It is likely that small amounts of turbulence kinetic energy available at the canopy top in stable conditions were rapidly dissipated inside the canopy. Other studies in broad-leaf forest canopies have indicated that the height of the minimum $S k_{w}$ within the canopy is stability dependent, and they agree that the most negative $S k_{w}$ is found in near-neutral conditions (e.g., Amiro, 1990a; Leclerc et al., 1990; Kruijt et al., 2000).

\subsection{TURBULENCE SPECTRA}

Composite power spectra were calculated for $\mathrm{u}, \mathrm{v}, \mathrm{w}$, and sonic temperatures according to the criteria discussed in Sections 3.3 and 3.4 (Figures 7 and 8). Power spectra for temperature calculated from thermocouple measurements will not be discussed, because the thermocouple time constants proved insufficient to resolve the high frequency roll-off adequately. In near-neutral conditions, the spectral distributions for the velocity components above canopy (Figures 7,8 ) were very similar to those commonly found in the surface layer, where an inertial subrange roll off of $\hat{f}^{-2 / 3}$ is predicted by Kolmogorov theory (e.g., Kaimal and Finnigan, 1994). This suggests that the turbulence above the canopy corresponds closely to equilibrium conditions. The spectra were characterized by a single maximum at $\hat{f}<1$. This value varies according to the velocity component and stability, and agrees with past work for flow over flat and uniform terrain (e.g., see Kaimal and Finnigan, 1994). In very unstable conditions, the peak position shifted towards lower frequencies, associated with strong convection and mixing that give rise to large eddies in the boundary layer above the canopy. In moderately stable and strongly stable conditions, the peaks shifted towards higher frequencies suggesting that the turbulence structures were smaller. The effect of stability on the spectral 

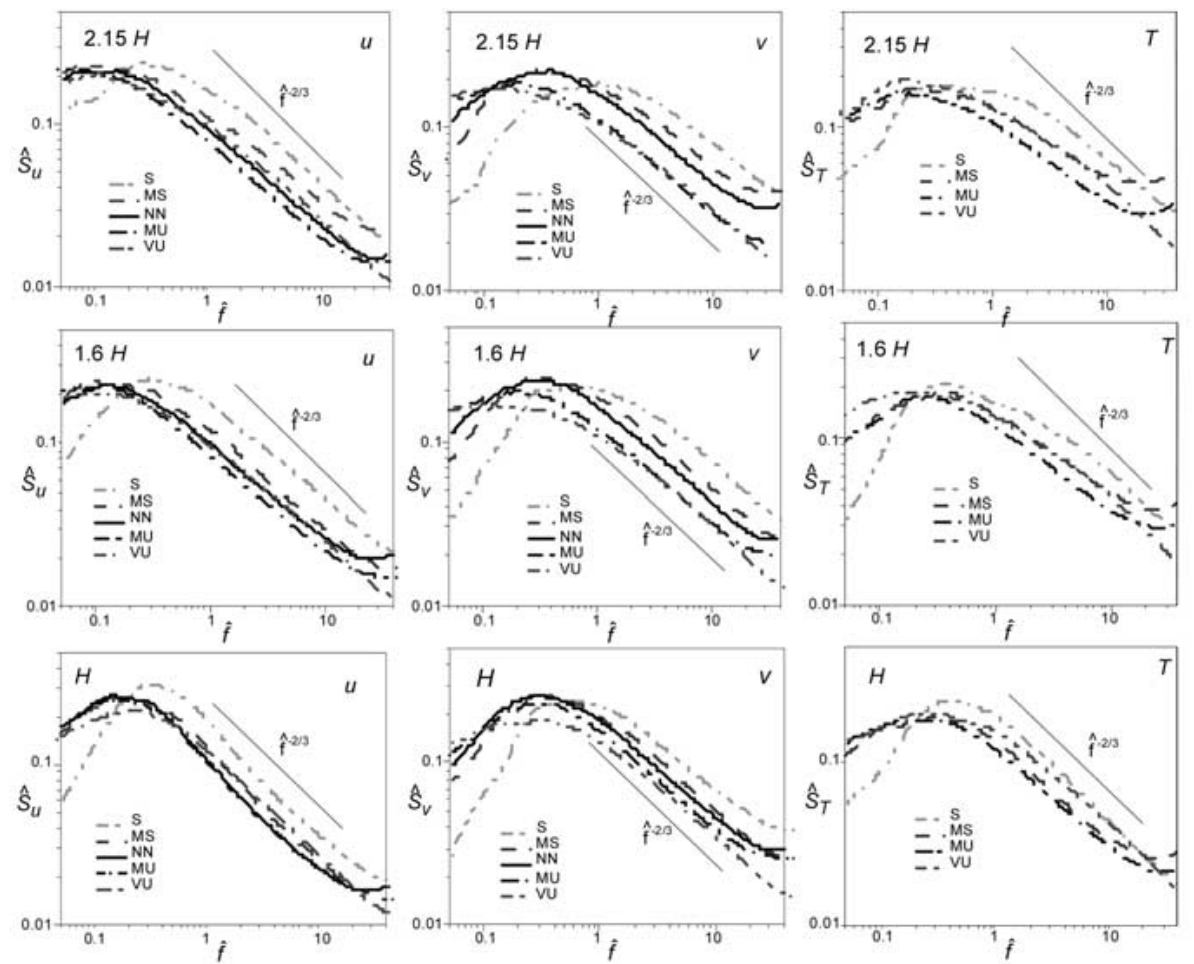

Figure 7. Normalized power spectra for the $u$ (left panels) and $v$ (middle panels) velocity components and sonic temperature $T$ (right panels) at different heights and stabilities above canopy (see also Table II).

distributions resulted in a general overall shift of the maximum in the spectral distributions, but did not affect the high frequency roll-off.

Composite power spectra for sonic temperatures above the vegetation have shapes similar to the velocity spectral distributions. Spectral peaks shifted with stability, but, as in the case of the velocity spectra, stability did not modify the rolloff at high frequencies significantly. The rates of decrease were generally very close to $\hat{f}^{-2 / 3}$. Temperature spectra in near-neutral conditions are likely to be dominated by noise, and are not shown here.

Kolmogorov equilibrium theory is not expected to be valid inside a vegetated canopy. However, the $w$-composite spectra below canopy (Figure 8) generally agree with data from comparable studies reported in the literature (e.g., Amiro, 1990b; Kruijt et al., 2000). The high frequency roll-off varied with height and was usually steeper than $\hat{f}^{-2 / 3}$. Some authors (e.g., Shaw and Seginer, 1985; Baldocchi and Hutchison, 1987; and recently Finnigan, 2000) found a different spectral rolloff in the vegetation and explained it in terms of a 'spectral shortcut' caused by a shift of energy from relatively large eddies directly to higher frequency wake turbulence. This process is thought to result from the interaction between the turbulent 

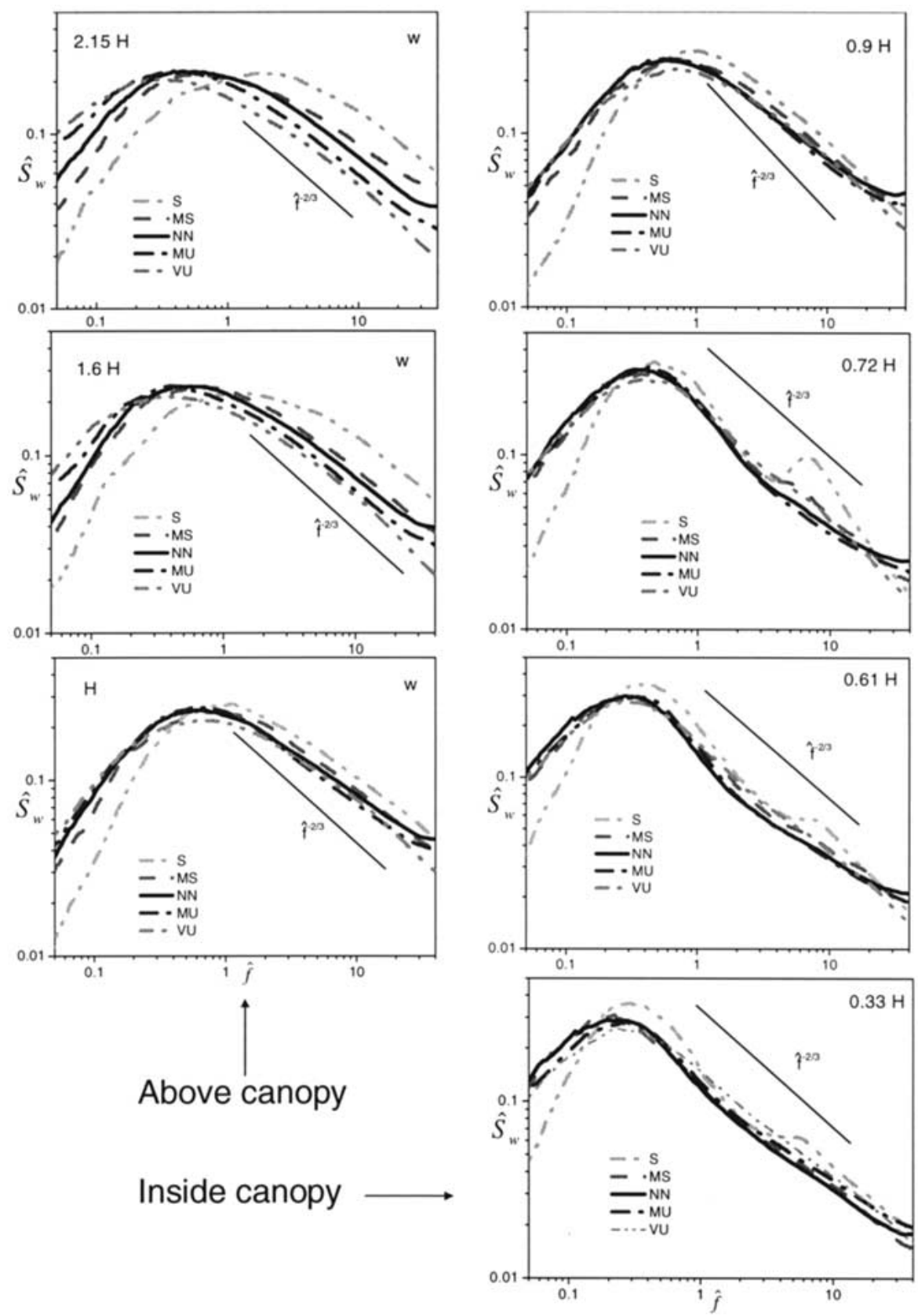

Figure 8 . Normalized power spectra $(\hat{S}$ vs. $\hat{f}$ ) for the $w$ velocity component at different heights and in different stability conditions (see also Table II). 
structures produced above the canopy, and the vegetation elements, which tend to break up large-scale eddies into smaller scale structures. Inside the canopy, the peaks of the spectral distributions were generally higher and sharper than above the canopy, suggesting that turbulent motion there comprised a smaller range of eddy scales, dominated by the large eddies that move through the canopy from above. This finding is supported by the picture of the motion provided by the vertical profiles of the $S k_{w}$ previously discussed (Figure 6f). Different stability conditions did not produce a marked shift of the spectral peak to higher or lower frequencies, as for surface-layer spectra. The maxima in the distributions for different heights were located at non-dimensional frequencies between $\hat{f} \approx 0.2$ to 1 (Figure 8 ). This figure indicates a slight systematic shift of the spectral peak towards lower frequency with increasing penetration into the canopy, in contrast to the notion that canopy turbulence scales with canopy height, rather than with height above ground (e.g., Brunet et al., 1994; Kaimal and Finnigan, 1994). However, in the limit (and considering the frequency scaling applied here), the spectral peak must shift to higher frequency (and thus smaller scales) as the forest floor is approached. Given the uncertainty of determining spectral peaks (compare Figure 3), the significance of this apparent shift to longer time scales is questionable, but encourages further inquiry into the effects of the canopy architecture on the distribution of length and time scales in forest canopy turbulence. An interpretation that this apparent shift represents the survival of primarily larger scale eddies (generated by shear instability at the canopy top) with increasing penetration into the canopy, must remain speculative with the presently available observations.

As expected, the marked organization of the spectra with respect to stability all but disappeared inside the canopy, except for the stable case, which showed a pronounced reduction in the lower frequency range. In the stable case, a relative maximum or shoulder was often detected in the higher frequency range at lower levels in the canopy (Figure 8). This feature was also reported in other works such as Amiro (1990b) and Kruijt et al. (2000). The latter authors suggested possible explanations for such behaviour in terms of physical processes that generate turbulence kinetic energy at high frequencies (e.g., wake turbulence) or due to instrument noise. Although physical processes can offer a plausible explanation, they need to be carefully examined before causalities can be established. Here, we are more inclined to attribute the presence of the high frequency anomaly to the increased relative level of noise during stable conditions, when turbulence is suppressed.

\section{Discussion and Conclusions}

Villani (2002) examined the sensitivity of a Lagrangian Stochastic (LS) model to variations in turbulence parameterizations in a forest canopy. The model results were shown to be sensitive to the shape of the vertical turbulence profiles, within 


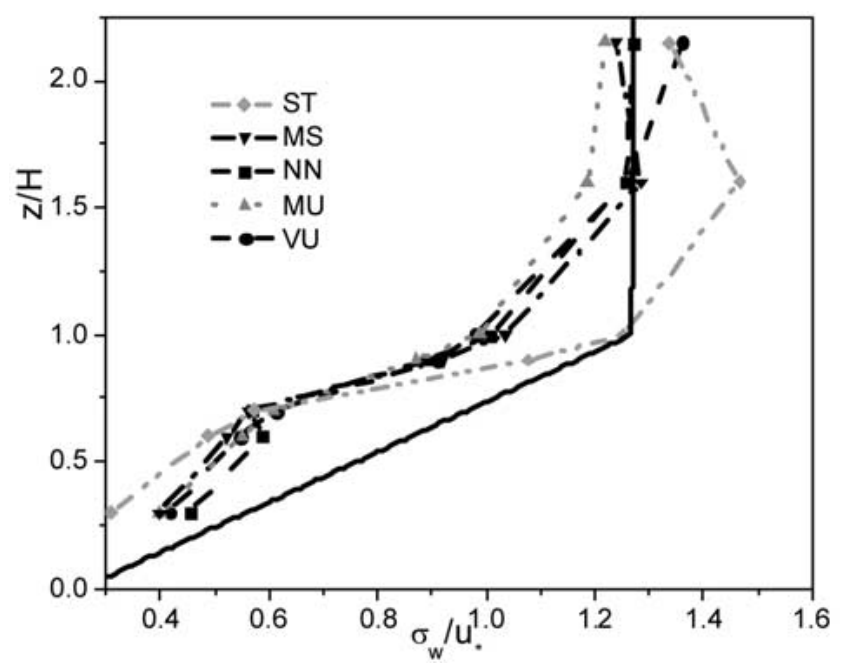

Figure 9. Comparison between normalized vertical velocity standard deviation profiles measured in this study in different stability conditions (dashed lines and symbols) and a parameterization used in Lagrangian stochastic models (bold line, from Rannik et al., 2000).

a layer that extends to more than twice the canopy height. In the present work, we showed that the profiles of turbulence statistics in a forest environment can vary considerably with stability, in particular above the canopy. Below canopy, turbulence statistics seems to be generally invariant with stability. A close relation between the overall shape of profiles and the canopy architecture is apparent in our results of the vertical velocity statistics (see also Raupach et al., 1996; Brunet et al., 1994, for a comparison), but a better vertical resolution is required to associate turbulence parameterizations with the detailed canopy architecture (e.g., the vegetation density profile).

With improved knowledge of the dependence of the flow properties on stability and canopy architecture, LS models can be more widely applied in vegetated environments. So far, LS model applications have been restricted to near-neutral conditions in the canopy layer, and to very simple forest architecture. Figure 9 shows a comparison between normalized vertical profiles of vertical velocity standard deviation measured in this study and a common form of parameterization for $\sigma_{w} / u_{*}$ in LS model applications. Clearly, the structure of the measured profiles in this Figure shows variations with stability. Even in the near-neutral case, the parameterization seems to be too much simplified compared to the measured profile. The modelled profile cannot detect the flow variations in the canopy layer as seen in the measured profile, which shows a non-linear decrease in the canopy layer, resulting from the properties of the canopy architecture and flow structure.

Our measurements of wind velocity and temperature statistics taken at the University of Michigan Biological Station lead to the following conclusions: 
- Different stability conditions in the surface layer above the canopy can produce changes in the vertical turbulence statistics profiles and power spectra above the canopy. In particular, vertical profiles indicate that during unstable surfacelayer conditions the major source of available energy is located at the canopy top, which drives the convective motion in the layers above.

- Vertical velocity power spectra inside the canopy show comparatively little dependence on the stability conditions at twice the canopy height, with the exception of the strongly stable case, where low frequencies inside the canopy are suppressed.

- In stable conditions the flow above about twice the canopy height often appears to be decoupled from conditions below (see also the previous point).

- Vertical velocity skewness within the canopy is strongly negative, due to high velocity sweeps and gusts that are generated at the canopy top. The skewness profile below canopy is often non-monotonic and dependent on surface-layer stability. The impact of sweeps and gusts is particularly intense during nearneutral conditions, when buoyancy effects are negligible.

- Whereas stability variations produce an overall shift in the velocity spectra above canopy, without altering their roll-off rate, this spectral shift does not occur within the canopy, and spectral roll-off rates do not show considerable variations with above-canopy stability.

- A slight shift of spectral peaks towards larger scales with increasing penetration into the canopy cannot be substantiated with the present data. A speculative interpretation that this represents the survival of primarily larger eddies (generated at the canopy top) with increasing depth, encourages a detailed investigation of the influence of canopy architecture on the distribution of length and time scales in forest canopy turbulence.

\section{Acknowledgements}

This research was supported in part by the Biological and Environmental Research Program (BER), U.S. Department of Energy (US-DoE), through the Midwestern Regional Center of the National Institute for Global Environmental Change (NIGEC) under Cooperative Agreement No. DE-FC03-90ER61010, and through a subcontract with Harvard University from the Terrestrial Carbon Program (TCP, US-DoE). The support of the University of Michigan Biological Station and its staff is greatly appreciated. We are indebted to an anonymous reviewer for pointing out the apparent spectral shift of peak frequencies below canopy. All opinions, findings, conclusions, and recommendations expressed in this publication are those of the authors and do not necessarily reflect the views of US-DoE. 


\section{References}

Amiro, B. D.: 1990a, 'Comparison of Turbulence Statistics within Three Boreal Forest Canopies', Boundary-Layer Meteorol. 51, 99-121.

Amiro, B. D.: 1990b, 'Drag Coefficients and Turbulence Spectra within Three Boreal Forest Canopies', Boundary-Layer Meteorol. 52, 227-246.

Baldocchi, D. and Hutchison, B. A.: 1987, 'Turbulence in an Almond Orchard: Vertical Variations in Turbulent Statistics', Boundary-Layer Meteorol. 40, 127-146.

Baldocchi, D. D. and Meyers, T. P.: 1988, 'Turbulence Structure in a Deciduous Forest', BoundaryLayer Meteorol. 43, 345-364.

Baldocchi, D. D., Finnigan, J. J., Wilson, K., Paw U, K. T., and Falge, E.: 2000, 'On Measuring Net Ecosystem Carbon Exchange over Tall Vegetation on Complex Terrain', Boundary-Layer Meteorol. 96, 257-291.

Brunet, Y., Finnigan, J. J., and Raupach, M. R.: 1994, 'A Wind Tunnel Study of Air Flow in Waving Wheat: Single-Point Velocity Statistics', Boundary-Layer Meteorol. 70, 95-132.

Campbell, G. S. and Norman, J. M.: 1998, An Introduction to Environmental Biophysics, 2nd edn., Springer-Verlag, New York, 286 pp.

Campbell Scientific, Inc: 1998, CSAT Three Dimensional Sonic Anemometer Instruction Manual, Logan, UT, 14 pp.

Chen, F. and Schwerdtfeger, P.: 1989, 'Flux-Gradient Relationships for Momentum and Heat over a Rough Natural Surface', Quart. J. Roy. Meteorol. Soc. 115, 335-352.

Cleveland, W. S.: 1979, 'Robust Locally Weighted Regression and Smoothing Scatterplots', J. Amer. Statist. Assoc. 74, 829-836.

Finnigan, J. J.: 2000, ‘Turbulence in Plant Canopies', Annu. Rev. Fluid Mech. 32, 519-571.

Gao, W., Shaw, R. H., and Paw U, K. T.: 1989, 'Observation of Organized Structure in Turbulent Flow within and above a Forest Canopy', Boundary-Layer Meteorol. 47, 349-377.

Garratt, J. R.: 1978, 'Transfer Characteristics for a Heterogeneous Surface of Large Aerodynamic Roughness', Quart. J. Roy. Meteorol. Soc. 104, 491-502.

Garratt, J. R.: 1992, The Atmospheric Boundary Layer, Cambridge University Press, Cambridge, 316 pp.

Högström, U., Bergström, H., Smedman, A-S., Halldin, S., and Lindroth, A.: 1989, 'Turbulent Exchange above a Pine Forest, I: Fluxes and Gradients', Boundary-Layer Meteorol. 49, 197-217.

IPCC: 2001, Climate Change 2001: The Scientific Basis, Contribution of Working Group I to the Third Assessment Report of the Intergovernmental Panel on Climate Change (IPCC), in J. T. Houghton, Y. Ding, D. J. Griggs, M. Noguer, P. J. van der Linden, and D. Xiaosu (eds.), Cambridge University Press, U.K., 944 pp.

Kaimal, J. C. and Finnigan, J. J.: 1994, Atmospheric Boundary Layer Flow: Their Structure and Measurement, Oxford University Press, New York, 289 pp.

Kruijt, B., Malhi, Y., Lloyd, J., Nobre, A. D., Miranda, A. C., Pereira, M. G. P., Culf, A., and Grace, J. J.: 2000, 'Turbulence Statistics above and within Two Amazon Rain Forest Canopies', BoundaryLayer Meteorol. 94, 297-331.

Justice, J. H.: 1981, 'The Step from One to Higher Dimensional Signal Processing - Case Histories', in D. F. Findley (ed.), Applied Time Series Analysis II, Acadia Press, 798 pp.

Leclerc, M. Y., Beissner, K. C., Shaw, R. H., Denhartog, G., and Neumann, H. H.: 1990, 'The Influence of Atmospheric Stability on the Budgets of the Reynolds Stress and Turbulent Kinetic Energy within and above a Deciduous Forest', J. Appl. Meteorol. 29, 916-933.

McMillen, R. T.: 1988, 'An Eddy Correlation Technique with Extended Applicability to Non-Simple Terrain', Boundary-Layer Meteorol. 43, 231-245.

Oke, T. R.: 1987, Boundary Layer Climates, 2nd edn., Routledge, London, 435 pp. 
Pearsall, D. R.: 1995, Landscape Ecosystems of the University of Michigan Biological Station, Northern Lower Michigan: Ecosystem Diversity and Biological Diversity, Ph.D. Thesis, University of Michigan, Ann Arbor.

Press, W. H., Teukolsky, S. A., Vetterling, W. T., and Flannery, B. P.: 1997, Numerical Recipes in Fortran 77, Volume I, 2nd edn., Cambridge University Press, 933 pp.

Rannik, Ü., Aubinet, M., Kurbanmuradov, O., Sabelfeld, K. K., Markkanen, T., and Vesala, T.: 2000, 'Footprint Analysis for Measurements over a Heterogeneous Forest', Boundary-Layer Meteorol. 97, 137-166.

Roth, M.: 2000, 'Review of Atmospheric Turbulence over Cities', Quart. J. Roy. Meteorol. Soc. 126, 941-990.

Raupach, M. R., 1989: 'Applying Lagrangian Fluid-Mechanics to Infer Scalar Source Distributions from Concentration Profiles in Plant Canopies', Agric. For. Meteorol. 47, 85-108.

Raupach, M. R., Finnigan, J. J., and Brunet, Y.: 1996, 'Coherent Eddies and Turbulence in Vegetation Canopies: The Mixing-Layer Analogy’. Boundary-Layer Meteorol. 78, 351-382.

Raupach, M. R., Thom, A. S., and Edwards, I.: 1980, 'A Wind-Tunnel Study of Turbulent Flow Close to Regularly Arrayed Rough Surfaces', Boundary-Layer Meteorol. 18, 373-397.

Schmid, H. P.: 2002, 'Footprint Modeling for Vegetation Atmosphere Exchange Studies: A Review and Perspective', Agric. For. Meteorol. 113, 159-184.

Schmid, H. P., Grimmond, C. S. B., Cropley, F., Offerle, B., and Su, H.-B.: 2000, 'Measurements of $\mathrm{CO}_{2}$ and Energy Fluxes over a Mixed Hardwood Forest in the Mid-Western United States', Agric. For. Meteorol. 103, 357-374.

Schmid, H. P., Su, H.-B., Vogel, C. S., and Curtis, P. S.: 2003, 'Ecosystem - Atmosphere Exchange of Carbon Dioxide over a Mixed Hardwood Forest in Northern Lower Michigan', J. Geophys. Res., in press.

Shaw, R. H. and Seginer, I.: 1985, 'The Dissipation of Turbulence in Plant Canopies', in 7th Symposium on Turbulence and Diffusion, preprint volume, AMS, Boston, MA, pp. 200-203.

Simpson, I. J., Thurtell, G. W., Neumann, H. H, Den Hartog, G., and Edwards, G. C.: 1998, 'The Validity of the Similarity Theory in the Roughness Sublayer above the Forest', Boundary-Layer Meteorol. 87, 69-99.

Stull, R. B.: 1988, An Introduction to Boundary Layer Meteorology, Kluwer Academic Publishers, Dordrecht, $666 \mathrm{pp}$

Su, H.-B., Shaw, R. H., Paw U, K. T., Moeng, C. H., and Sullivan, P. P.: 1998, 'Turbulent Statistics of Neutrally Stratified Flow within and above a Sparse Forest from Large-Eddy Simulation and Field Observations', Boundary-Layer Meteorol. 88, 363-397.

Su, H.-B., Shaw, R. H., and Paw U, K. T.: 2000a, 'Two-Point Correlation Analysis of Neutrally Stratified Flow within and above a Forest from Large-Eddy Simulation', Boundary-Layer Meteorol. 94, 423-460.

Su, H.-B., Schmid, H. P., Grimmond, C. S. B., Vogel, C. S., and Curtis, P. S.: 2000b, 'Temporal and Spatial Variability of Mean Flow and Turbulence Characteristic over a Deciduous Forest', in Preprints, 14th Symposium on Boundary Layers and Turbulence, 7-11 August 2000, Aspen, CO, American Meteorological Society, Boston, MA, pp. 318-321.

Villani, M. G.: 2002, Turbulence and Diffusion in and over a Forest Environment: Measurements and Modeling, M.S. Thesis, Indiana University, Bloomington, IN, 77 pp. 